\title{
BMJ Open A favourable prognostic marker for EGFR mutant non-small cell lung cancer: immunohistochemical analysis of MUC5B
}

Kouki Wakata, ${ }^{1}$ Tomoshi Tsuchiya, ${ }^{1}$ Koichi Tomoshige, ${ }^{1}$ Katsunori Takagi, ${ }^{1}$ Naoya Yamasaki, ${ }^{1}$ Keitaro Matsumoto, ${ }^{1}$ Takuro Miyazaki, ${ }^{1}$ Atsushi Nanashima, ${ }^{1}$ Jeffrey A Whitsett, ${ }^{2}$ Yutaka Maeda, $^{2}$ Takeshi Nagayasu ${ }^{1}$

To cite: Wakata K, Tsuchiya $\mathrm{T}$, Tomoshige $\mathrm{K}$, et al. A favourable prognostic marker for EGFR mutant nonsmall cell lung cancer: immunohistochemical analysis of MUC5B. BMJ Open 2015;5:e008366. doi:10.1136/bmjopen-2015008366

- Prepublication history and additional material is available. To view please visit the journal (http://dx.doi.org/ 10.1136/bmjopen-2015008366).

Received 30 March 2015 Revised 8 May 2015 Accepted 13 May 2015 CrossMark

\footnotetext{
${ }^{1}$ Division of Surgical Oncology, Nagasaki University Graduate School of Biomedical Sciences, Nagasaki, Japan

2Division of Neonatology, Perinatal and Pulmonary Biology, Perinatal Institute, Cincinnati Children's Hospital Medical Center and the University of Cincinnati College of Medicine, Cincinnati, Ohio, USA

Correspondence to Dr Yutaka Maeda; yutaka.maeda@cchmc.org; Dr Takeshi Nagayasu; nagayasu@nagasaki-u.ac.jp
}

\section{ABSTRACT}

Objectives: To determine the use of the mucin proteins MUC5B and MUC5AC as prognosis markers for non-small cell lung cancer (NSCLC) carrying epidermal growth factor receptor (EGFR) mutations.

Setting: Patients who underwent surgical resection at Nagasaki University Hospital and related facilities in Japan between June 1996 and March 2013.

Participant: 159 Japanese patients (male: $n=103$; female: $\mathrm{n}=56$ ) with NSCLC, who underwent surgical resection (EGFR-mutant type: $\mathrm{n}=78$, EGFR wild type: $\mathrm{n}=81$ ).

Results: Patients whose tumours expressed MUC5B had significantly longer overall survival and relapse-free survival compared to the MUC5B-negative patients with EGFR mutant NSCLC ( $\mathrm{p}=0.0098$ and $\mathrm{p}=0.0187$, respectively). In patients with EGFR wild-type NSCLC, there was no association with MUC5B expression. MUC5AC expression was not different between EGFR mutant and wild-type NSCLC.

Conclusions: Present findings indicate that MUC5B, but not MUC5AC, is a novel prognostic biomarker for patients with NSCLC carrying EGFR mutations but not for patients with NSCLC carrying wild-type EGFR.

\section{INTRODUCTION}

Lung cancer is the primary cause of cancerrelated death in the USA and worldwide. ${ }^{1}$ Non-small cell lung cancer (NSCLC) accounts for approximately $80-85 \%$ of all lung cancers. ${ }^{1}$ Currently, targeted therapies for non-resectable NSCLC have progressed rapidly, based on the discovery of pharmacologically treatable driver mutations in epidermal growth factor receptor (EGFR) and fusions of anaplastic lymphoma kinase (ALK). ${ }^{2}{ }^{3}$ These moleculary targeted therapies have revealed distinct and/or overlapping tumorigenic pathways associated with each driver mutation, especially regarding the

\section{Strengths and limitations of this study}

- A prognostic marker for each driver mutation in non-small cell lung cancer (NSCLC) has not yet been determined.

- MUC5B is a favourable postoperative prognostic marker for epidermal growth factor receptor (EGFR) mutant NSCLC

- MUC5AC is not correlated with postoperative prognosis regardless of EGFR mutation status.

- The function of MUC5B in EGFR mutant NSCLC remains unknown.

mechanisms of tumour recurrence. ${ }^{4}$ Genetic screening of driver mutations, including $E G F R$ mutations and $A L K$ fusions, is now common for metastatic NSCLC but not for surgically resected primary NSCLC. ${ }^{5}$ In the ALCHEMIST lung cancer trials (http://www. cancer.gov/researchandfunding/areas/clinicaltrials/nctn/alchemist), patients whose primary lung tumours carry EGFR mutations (EGFRmutant patients) are being tested for adjuvant therapy of erlotinib targeting EGFR mutations. However, a favourable or poor prognostic biomarker associated with EGFR mutations is not known. Such biomarkers will be useful to determine EGFR-mutant patients who would benefit most from the adjuvant therapy of erlotinib and to avoid such unnecessary therapy after surgery in patients who would not benefit.

Recently, we reported that decreased expression of $N k \times 2-1$ (also known as TTF-1) in a mouse model of EGFR mutant NSCLC reduced the number and size of lung tumours, ${ }^{6}$ and extended the survival of the mice (see online supplementary figure S1). Unexpectedly, the decreased Nkx2-1 induced the expression of a mucin protein MUC5B but not MUC5AC in EGFR-mutant 
lung tumours in the mice, ${ }^{6}$ suggesting that MUC5B may serve as a favourable prognostic marker associated with EGFR mutant NSCLC in humans. In the present study, we assessed whether the expression of MUC5B in the primarily resected EGFR mutant or wild-type lung tumours is linked to survival of the patients after surgery. Our study provides a novel approach to assess prognosis for patients whose primarily resected lung tumours carry EGFR mutations.

\section{METHODS}

\section{Study population}

Among the patients who underwent surgical resection at Nagasaki University Hospital and related facilities between June 1996 and March 2013, patients who were tested for the presence or absence of EGFR mutations were selected for this study. The EGFR mutations were confirmed internally or externally (LSI Medience Corporation, Japan). We further selected the patients whose clinicopathological characteristics were retrieved from the patients' charts and whose prognosis was followed at our institution and related facilities. We enrolled 159 patients (EGFR-mutant type: n=78, EGFR wild type: $\mathrm{n}=81$ ) for this study (table 1 ). All investigations were approved by our institution and related facilities' review boards, and informed consent was obtained from all participants prior to the study.

\section{Clinicopathological evaluation}

Histological classification of NSCLC was designated as three types-well, moderately and poorly differentiated -based on the predominant features according to the WHO classification. ${ }^{7}$ The patients remained for a median follow-up period of 1680 days, ranging from 55 to 4503 days. For all patients, periodic inspection with chest X-ray, CT scan and tumour marker assays was performed at least every 6 months to confirm the presence or absence of recurrence, even if patients experienced no problems or no symptoms.

\section{Antibody information}

For immunohistochemical staining, primary antibodies were used at the following concentrations: rabbit polyclonal anti-MUC5B (1:200; sc-20 119, Santa Cruz Biotechnology) and rabbit polyclonal anti-MUC5AC (1:50; sc-20 118, Santa Cruz Biotechnology).

\section{Sample preparation, selection and immunohistochemistry}

The $5 \mu \mathrm{m}$ thick formalin-fixed paraffin-embedded (FFPE) lung sections were deparaffinised in dimethylbenzene and dehydrated through a graded alcohol series. For antigen retrieval, the FFPE lung sections were incubated in $10 \mathrm{mM}$ citric acid $\left(\mathrm{pH}\right.$ 6) at $121^{\circ} \mathrm{C}$ for $15 \mathrm{~min}$ and then washed in phosphate-buffered saline (PBS). Next, the lung sections were immersed in 3\% $\mathrm{H}_{2} \mathrm{O}_{2}$ solution for 30 min to block the endogenous peroxidase followed by incubation with each primary antibody at $4^{\circ} \mathrm{C}$ overnight. After washing in PBS, the lung sections were incubated with the peroxidaseconjugated secondary antibodies (Simple Stain MAX-PO kit, Nichirei, Tokyo, Japan) for $30 \mathrm{~min}$ at room temperature. For immunohistochemistry (IHC) staining, the lung sections were visualised with a diaminobenzidine (DAB: brown) kit (Histofine, Nichirei) and counterstained with H\&E. The lung sections visualised with

\begin{tabular}{|c|c|}
\hline \multicolumn{2}{|l|}{ Number of patients } \\
\hline Median age (range, years) & $67.5(32-90)$ \\
\hline \multicolumn{2}{|l|}{ Gender } \\
\hline Male & $103(65 \%)$ \\
\hline Female & $56(35 \%)$ \\
\hline \multicolumn{2}{|l|}{ Smoking status } \\
\hline Non-smoker & $54(34 \%)$ \\
\hline Smoker & $105(66 \%)$ \\
\hline \multicolumn{2}{|l|}{ Histological type } \\
\hline Adenocarcinoma: bronchoalveolar & $33(21 \%)$ \\
\hline Adenocarcinoma & $91(57 \%)$ \\
\hline Squamous cell carcinoma & $32(20 \%)$ \\
\hline Adenosquamous carcinoma & $2(1 \%)$ \\
\hline Other ${ }^{*}$ & $1(1 \%)$ \\
\hline Median tumour size (range, mm) & $32.4(8-120)$ \\
\hline \multicolumn{2}{|l|}{ Degree of differentiation } \\
\hline Well & $55(35 \%)$ \\
\hline Moderately & 69 (43\%) \\
\hline Poorly & $28(18 \%)$ \\
\hline MD & $7(4 \%)$ \\
\hline \multicolumn{2}{|l|}{ Stage } \\
\hline $\mathrm{IA} / \mathrm{IB}$ & $81(51 \%)$ \\
\hline IIA/IIB & $40(25 \%)$ \\
\hline IIIA/IIIB & $38(24 \%)$ \\
\hline \multicolumn{2}{|l|}{ Tumour status } \\
\hline $\mathrm{T} 1-2$ & $136(86 \%)$ \\
\hline T3-4 & $23(14 \%)$ \\
\hline \multicolumn{2}{|l|}{ Nodal status } \\
\hline No & $103(65 \%)$ \\
\hline N1-3 & $56(35 \%)$ \\
\hline \multicolumn{2}{|l|}{ Lymphatic invasion } \\
\hline Negative & $56(35 \%)$ \\
\hline Positive & 102 (64\%) \\
\hline MD & $1(1 \%)$ \\
\hline \multicolumn{2}{|l|}{ Venous invasion } \\
\hline Negative & $76(48 \%)$ \\
\hline Positive & $82(52 \%)$ \\
\hline $\mathrm{MD}$ & $1(1 \%)$ \\
\hline \multicolumn{2}{|l|}{ Adjuvant chemotherapy } \\
\hline Yes & $85(53 \%)$ \\
\hline No & $74(47 \%)$ \\
\hline \multicolumn{2}{|l|}{ EGFR } \\
\hline Wild type & $81(51 \%)$ \\
\hline Mutant type & $78(49 \%)$ \\
\hline
\end{tabular}


Figure 1 Immunohistochemical staining for MUC5B and MUC5AC expression in NSCLC. Representative images of immune-positive staining for MUC5B in non-small cell lung cancer $(A)$, negative staining $(B)$, positive staining for MUC5AC (C) and negative staining (D).

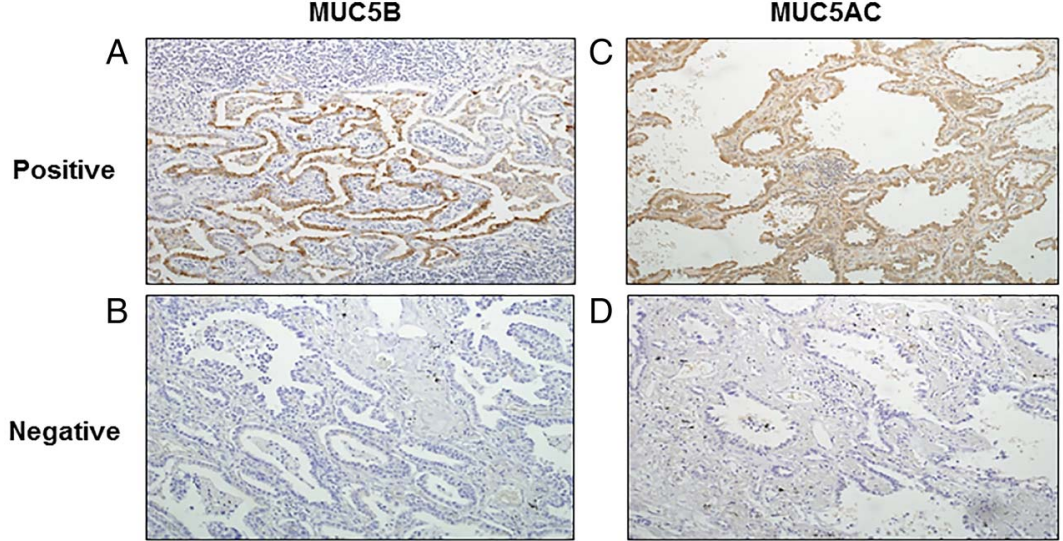

DAB were dehydrated with alcohol and dimethylbenzene and mounted in a conventional fashion.

Normal bronchial tissue specimens that moderately expressed MUC5B were prepared as positive controls in all cases. Normal gastric mucosa tissue specimens that moderately expressed MUC5AC were prepared as positive controls in all cases. Negative controls were also prepared in all cases. MUC5B and MUC5AC staining was evaluated by IHC by two independent trained observers (KW and TT). The pathological criteria were determined by reference to guideline for human epidermal growth factor receptor 2 (Her2/neu) testing in breast cancer (score 0, no staining observed or incomplete faint/barely perceptible cytoplasmic staining of $<10 \%$ of tumour cells; score 1, incomplete faint/barely perceptible cytoplasmic staining of $>10 \%$ of tumour cells; score 2 , incomplete weak/moderate cytoplasmic staining of $>10 \%$ of tumour cells; score 3, complete and intense cytoplasmic staining of $>30 \%$ of tumour cells). ${ }^{8}$ Scores 0 and 1 were further categorised as negative, and scores 2 and 3 as positive.

\section{Statistical analysis}

For univariate analysis, categorical data were analysed by the $\chi^{2}$ test, Fisher's exact test or the Cochran-Armitage test. Continuous data were expressed as a mean using the Mann-Whitney $\mathrm{U}$ test or the Kruskal-Wallis test. The overall survival (OS) and relapse-free survival (RFS) were calculated according to the Kaplan-Meier method, and differences between groups were tested for significance using the log-rank test. Participants who neither died nor had recurrence were censored at the time of their last follow-up. The prognostic relevance of a single factor was determined by multivariate Cox regression analysis. A p value of 0.05 or less was considered significant. SPSS V.17 software (SPSS Japan, Tokyo, Japan) was used for the analysis.

\section{RESULTS}

Expression of MUC5B and MUC5AC in human NSCLC

Since MUC5B is an abundant cytoplasmic and secreted protein, we assessed whether MUC5B could be used as a prognostic marker for patients with NSCLC carrying EGFR mutations in primary resected human lung tumours. Primary resected NSCLC tumours were tested immunohistochemically for the presence of MUC5B. MUC5B staining was detected in the cytoplasm of NSCLC cells in 27 of the 78 samples with EGFR mutations and 29 of the 81 samples with wild-type $E G F R$ (figure 1A, B). The NSCLC samples were also tested using MUC5AC antibody, detecting expression of MUC5AC in the cytoplasm of NSCLC cells in 20 of the 73 samples with EGFR mutations and 24 of the 79 samples with wild-type EGFR (figure 1C, D). These results indicate that both MUC5B and MUC5AC are expressed in a portion of human NSCLC.

\section{Prognostic association of MUC5B or MUC5AC with EGFR mutant or wild-type NSCLC}

Expression of MUC5B in NSCLC tumours carrying EGFR mutations was not correlated with clinicopathological parameters, including age, gender, smoking status, histological type, tumour size, degree of differentiation, stage, tumour status, nodal status, lymphatic invasion, venous invasion or adjuvant chemotherapy (table 2). Expression of MUC5B in NSCLC tumours with wild-type EGFR was not correlated with all of the clinicopathological parameters but was correlated with the histological type (see online supplementary table S1).

OS and RFS for patients with NSCLC carrying EGFR mutations or wild-type EGFR were assessed. In a cohort of patients whose resected NSCLC tumours carried EGFR mutations, univariate analysis showed significant differences $(p<0.05)$ in OS in expression of MUC5B, tumour size, histological type, degree of differentiation, stage, lymphatic invasion and venous invasion, and in RFS in expression of MUC5B, tumour size, degree of differentiation, stage, lymphatic invasion and venous invasion (table 3). Patients whose tumours expressed MUC5B (MUC5B-positive patients) survived significantly longer than patients whose tumours did not express MUC5B (MUC5B-negative patients) in both OS (5-year OS; $95.8 \%$ vs $65.1 \%, \mathrm{p}=0.0098$; figure 2A) and RFS (5-year RFS; $69.9 \%$ vs $44 \%, \mathrm{p}=0.0187$; figure 2B). 
Table 2 Association with clinicopathological data and the expression of MUC5B of patients with EGFR-mutant NSCLC

\begin{tabular}{|c|c|c|c|c|}
\hline \multirow[b]{2}{*}{ Parameters } & \multirow[b]{2}{*}{$\begin{array}{l}\text { Total } \\
(n=78)\end{array}$} & \multicolumn{2}{|l|}{ MUC5B } & \multirow[b]{2}{*}{ p Value } \\
\hline & & $\begin{array}{l}\text { Negative (-) } \\
(n=51)\end{array}$ & $\begin{array}{l}\text { Positive (+) } \\
(\mathrm{n}=27)\end{array}$ & \\
\hline Median age (range, years) & $66.9(41-85)$ & $66.7(42-83)$ & $67.3(41-85)$ & 0.674 \\
\hline \multicolumn{5}{|l|}{ Gender } \\
\hline Male & $35(45 \%)$ & $22(28 \%)$ & $13(17 \%)$ & \\
\hline Female & $43(55 \%)$ & $29(37 \%)$ & $14(18 \%)$ & 0.6721 \\
\hline \multicolumn{5}{|l|}{ Smoking status } \\
\hline Non-smoker & $42(54 \%)$ & $28(36 \%)$ & $14(18 \%)$ & \\
\hline Smoker & $36(46 \%)$ & $23(29 \%)$ & $13(17 \%)$ & 0.7971 \\
\hline \multicolumn{5}{|l|}{ Histological type } \\
\hline Adenocarcinoma: bronchoalveolar & 27 (35\%) & $16(21 \%)$ & $11(14 \%)$ & \\
\hline Adenocarcinoma & $43(55 \%)$ & $29(37 \%)$ & $14(18 \%)$ & \\
\hline Squamous cell carcinoma & $8(10 \%)$ & $6(8 \%)$ & $2(3 \%)$ & 0.6522 \\
\hline Median tumour size (range, $\mathrm{mm}$ ) & $25.7(8-60)$ & $26.1(8-60)$ & $24.9(8-50)$ & 0.8771 \\
\hline \multicolumn{5}{|l|}{ Degree of differentiation } \\
\hline Well & $35(45 \%)$ & $22(28 \%)$ & $13(17 \%)$ & \\
\hline Moderately & $28(36 \%)$ & $19(24 \%)$ & $9(12 \%)$ & \\
\hline Poorly & $11(14 \%)$ & $6(8 \%)$ & $5(6 \%)$ & 0.7348 \\
\hline MD & $4(5 \%)$ & $4(5 \%)$ & $0(0 \%)$ & \\
\hline \multicolumn{5}{|l|}{ Stage } \\
\hline IA/IB & $46(59 \%)$ & $29(37 \%)$ & $17(22 \%)$ & \\
\hline$\| A / I B$ & $14(18 \%)$ & $8(10 \%)$ & $6(8 \%)$ & \\
\hline IIIA/IIIB & $18(23 \%)$ & $14(18 \%)$ & $4(5 \%)$ & 0.4162 \\
\hline \multicolumn{5}{|l|}{ Tumour status } \\
\hline T1-2 & $68(87 \%)$ & 42 (54\%) & 26 (33\%) & \\
\hline T3-4 & 10 (13\%) & $9(12 \%)$ & $1(1 \%)$ & 0.0797 \\
\hline \multicolumn{5}{|l|}{ Nodal status } \\
\hline No & 53 (68\%) & 35 (45\%) & 18 (23\%) & \\
\hline $\mathrm{N} 1-3$ & 25 (32\%) & $16(21 \%)$ & $9(12 \%)$ & 0.8599 \\
\hline \multicolumn{5}{|l|}{ Lymphatic invasion } \\
\hline Negative & 35 (45\%) & 26 (33\%) & $9(12 \%)$ & \\
\hline Positive & 42 (54\%) & 24 (31\%) & $18(23 \%)$ & 0.1165 \\
\hline MD & $1(1 \%)$ & $1(1 \%)$ & $0(0 \%)$ & \\
\hline \multicolumn{5}{|l|}{ Venous invasion } \\
\hline Negative & 45 (58\%) & 30 (38\%) & 15 (19\%) & \\
\hline Positive & $32(41 \%)$ & $20(26 \%)$ & $12(15 \%)$ & 0.7057 \\
\hline MD & $1(1 \%)$ & $1(1 \%)$ & $0(0 \%)$ & \\
\hline \multicolumn{5}{|l|}{ Adjuvant chemotherapy } \\
\hline Yes & 33 (42\%) & 20 (26\%) & 13 (17\%) & \\
\hline No & 45 (58\%) & $31(40 \%)$ & 14 (18\%) & 0.4475 \\
\hline
\end{tabular}

Multivariate Cox regression analysis using the variables that were $\mathrm{p}<0.05$ in univariate analysis showed that the expression of MUC5B was independently associated with better OS and RFS $(\mathrm{p}<0.05$; table 4$)$. In a cohort of patients whose resected NSCLC tumours had wild-type $E G F R$, univariate analysis showed significant differences $(\mathrm{p}<0.05)$ in OS in smoking status, stage, venous invasion and adjuvant chemotherapy, and in RFS, lymphatic invasion and venous invasion (see online supplementary table S2). There was no significant difference between the MUC5B-positive patients and MUC5B-negative patients in OS and RFS (5-year OS; $59.5 \%$ vs $63.6 \%$, 5-year RFS; $36 \%$ vs $48.5 \%$, respectively, figure 2C, D). Expression of MUC5AC in NSCLC was not associated with OS and RFS regardless of EGFR mutation status (figure 3). These results indicate that MUC5B is a favourable prognostic marker for postoperative patients whose resected NSCLC tumours carry EGFR mutation but not for those with wild type-EGFR.

\section{DISCUSSION}

In the present study, we demonstrate that expression of MUC5B in primary EGFR mutant NSCLC is associated with longer survival in patients with NSCLC. MUC5B, but not MUC5AC, is a favourable prognostic biomarker for NSCLC in humans carrying EGFR mutations. Our study also indicates that adjuvant chemotherapy is not 
Table 3 Univariate analysis for OS and RFS in EGFR-mutant patients with NSCLC

\begin{tabular}{|c|c|c|c|c|c|}
\hline \multirow[b]{2}{*}{ Parameters } & \multirow[b]{2}{*}{$\mathbf{N}$} & \multicolumn{2}{|l|}{ os } & \multicolumn{2}{|l|}{ RFS } \\
\hline & & Survival (\%) & p Value & Survival (\%) & p Value \\
\hline \multicolumn{6}{|l|}{ Age (years) } \\
\hline$<70$ & 39 & 75.5 & & 63.6 & \\
\hline$\geq 70$ & 39 & 76.3 & 0.7311 & 41.5 & 0.1207 \\
\hline \multicolumn{6}{|l|}{ Gender } \\
\hline Male & 35 & 69 & & 54.4 & \\
\hline Female & 43 & 81.5 & 0.3166 & 51.8 & 0.813 \\
\hline \multicolumn{6}{|l|}{ Smoking status } \\
\hline Non-smoker & 43 & 75.9 & & 49.1 & \\
\hline Smoker & 36 & 73.3 & 0.9754 & 55.8 & 0.8508 \\
\hline \multicolumn{6}{|l|}{ MUC5B expression } \\
\hline Positive & 27 & 95.8 & & 69.9 & \\
\hline Negative & 51 & 65.1 & 0.0098 & 44 & 0.0187 \\
\hline \multicolumn{6}{|l|}{ Tumour size } \\
\hline$<20 \mathrm{~mm}$ & 25 & 95 & & 85.7 & \\
\hline$\geq 20 \mathrm{~mm}$ & 44 & 64.4 & 0.0058 & 31.2 & 0.0001 \\
\hline \multicolumn{6}{|l|}{ Histological type } \\
\hline Adenocarcinoma & 69 & 78.8 & & 54 & \\
\hline Squamous cell carcinoma & 8 & 46.9 & 0.0245 & 50 & 0.6369 \\
\hline \multicolumn{6}{|l|}{ Degree of differentiation } \\
\hline Well & 35 & 90 & & 72.6 & \\
\hline Moderately & 28 & 62.3 & & 34.5 & \\
\hline Poorly & 11 & 50.6 & 0.0172 & 38.1 & 0.0137 \\
\hline \multicolumn{6}{|l|}{ Stage } \\
\hline 1 & 45 & 87.8 & & 62.8 & \\
\hline$\|/\| I \|$ & 33 & 59.3 & 0.0095 & 38.8 & 0.0308 \\
\hline \multicolumn{6}{|l|}{ Lymphatic invasion } \\
\hline Negative & 35 & 92.3 & & 74.2 & \\
\hline Positive & 42 & 62.7 & 0.0075 & 35.8 & 0.0011 \\
\hline \multicolumn{6}{|l|}{ Venous invasion } \\
\hline Negative & 45 & 89 & & 66.5 & \\
\hline Positive & 32 & 55.7 & 0.0045 & 25.9 & 0.0021 \\
\hline \multicolumn{6}{|l|}{ Adjuvant chemotherapy } \\
\hline Yes & 33 & 62 & & 37.5 & \\
\hline No & 45 & 82.8 & 0.2569 & 63.4 & 0.0183 \\
\hline
\end{tabular}

effective for EGFR-mutant patients, suggesting that mutant EGFR-targeting drugs, including gefitinib or erlotinib, should be used as an adjuvant therapy mainly for MUC5B-negative EGFR-mutant patients who have a poorer prognosis than MUC5B-positive EGFR-mutant patients. Our results using MUC5B as a prognosis biomarker for EGFR-mutant patients should be integrated into the ALCHEMIST lung cancer trials to determine patients who would benefit most from the adjuvant therapy.

MUC5B has been assessed as a prognostic biomarker for multiple cancers in several studies, using reverse transcription-PCR, microarray analysis and IHC (see online supplementary table S3) ${ }^{9-14}$ Messenger RNA (mRNA) data assessing MUC5B as a prognostic biomarker is available at PrognoScan, a database for meta-analysis of the prognostic value of genes using microarray data deposited to the public domain. ${ }^{15}$ The prognostic impact of MUC5B expression differed among cancer types. In lung cancer, six microarray studies analysed by PrognoScan did not indicate MUC5B as either a good or a poor prognostic biomarker. ${ }^{16-21}$ Immunohistochemical analysis indicated MUC5B as a poor prognosis biomarker (see online supplementary table S3), ${ }^{9} 14$ a finding contradicting our present study. Previous mRNA microarray and immunostaining were based on all NSCLCs independent of driver mutationbased classification, which differs from our analysis, which was based on classification by EGFR mutations. The utility of MUC5B as a prognostic factor differed in the two breast cancer studies, depending on the molecular basis of the tumours. In all breast cancers, PrognoScan indicated that MUC5B was associated with poor prognosis; $;{ }^{22}{ }^{23}$ however, in (estrogen receptor-) positive breast cancers, MUC5B was associated with favourable prognosis, ${ }^{24}$ indicating the potential 
A

EGFR mutant type NSCLC

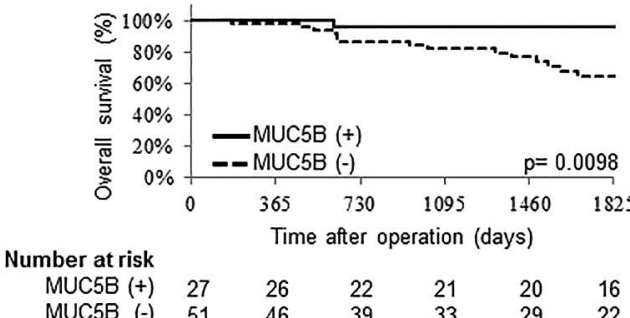

B

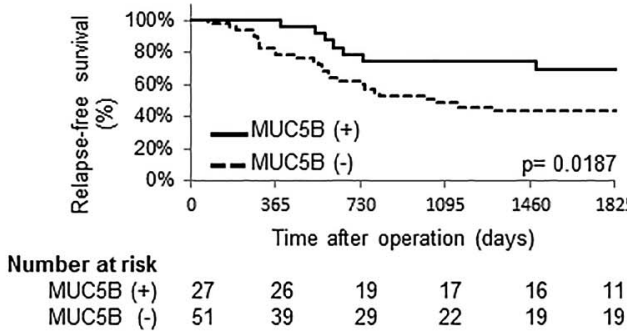

C

EGFR wild type NSCLC

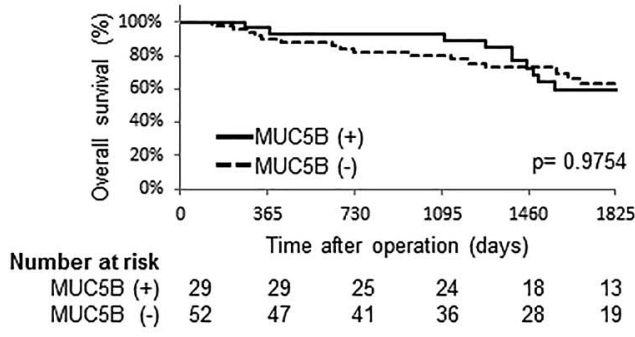

D

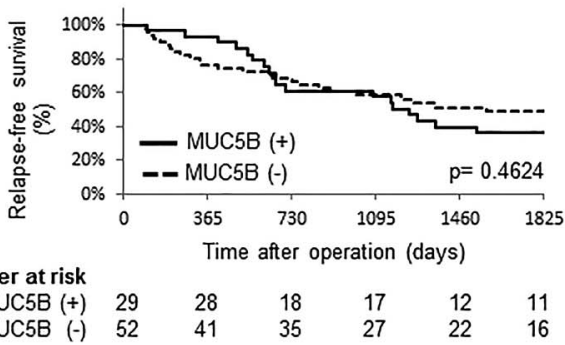

Figure 2 Survival curves for patients based on the expression of MUC5B in epidermal growth factor receptor (EGFR) mutant or wild-type non-small cell lung cancer (NSCLC). Overall and relapse-free survivals (OS and RFS) for patients with NSCLC carrying EGFR mutations or EGFR wild type. OS (A) RFS (B) in the patients with EGF- mutant type NSCLC and OS (C) and RFS (D) in the patients with EGFR wild-type NSCLC.

importance of tumour classification on a molecular basis. In the present study, we assessed MUC5B as a biomarker for NSCLC based on EGFR mutation status rather than on all NSCLCs, identifying MUC5B as a favourable prognosis biomarker for EGFR mutant NSCLC.

Regulation of MUC5B in EGFR mutant NSCLC is not well understood. MUC5AC and MUC5B genes are closely located at a locus on human chromosome 11. Both are evolutionally conserved gel-forming mucins secreted from airway epithelial cells in the lung. In normal lung, MUC5B is constitutively expressed at higher levels than MUC5AC. ${ }^{25}$ In asthma and other inflammatory lung diseases, MUC5AC is highly induced in airway goblet cells. ${ }^{25}$ In idiopathic pulmonary fibrosis (IPF), MUC5B but not MUC5AC is highly expressed in the airway goblet cells. ${ }^{26} 27$ The single-nucleotide polymorphism (SNP) rs35705950 located at the MUC5B promoter is associated with induction of MUC5B mRNA in IPF; ${ }^{27}$ however, we detected the SNP rs35705950 in only one of 27 cases in the EGFR mutant NSCLC expressing MUC5B (data not shown), indicating that the SNP is not associated with increased MUC5B in EGFR mutant NSCLC. Since MUC5B was induced in EGFR mutant lung tumours in $N k \times 2-1$ heterozygous mice $\left(\mathrm{EGFR}^{\mathrm{L} 858 \mathrm{R}}\right.$; $\left.\mathrm{Nkx} 2-1^{+/-}\right), M u c 5 b$ is suppressed by NKX2-1 in EGFR mutant NSCLC in mice. ${ }^{6}$ Regulatory mechanisms controlling the $M U C 5 B$ gene are not understood in EGFR mutant NSCLC in humans. The function of MUC5B in cancer has been analysed using a truncated MUC5B in MCF7 breast cancer cells, truncated MUC5B promoting tumourigenesis of MCF7 cells. ${ }^{13}$ However, the use of truncated MUC5B may obscure the intrinsic role of fulllength MUC5B since there is a possibility that the truncated MUC5B may function in a dominant-negative fashion. In lung, MUC5B is required for mucociliary

Table 4 Multivariate analysis for OS and RFS in EGFR-mutant patients with NSCLC

\begin{tabular}{|c|c|c|c|}
\hline & HR & $95 \% \mathrm{Cl}$ & p Value \\
\hline \multicolumn{4}{|l|}{ OS } \\
\hline MUC5B (positive vs negative) & 0.053 & 0.0064 to 0.4402 & 0.0065 \\
\hline Differentiation (well vs moderately vs poorly) & 0.3762 & 0.1357 to 1.0428 & 0.0602 \\
\hline Stage I vs stage II/III & 0.5199 & 0.1687 to 1.6019 & 0.2545 \\
\hline Lymphatic invasion (positive vs negative) & 2.9524 & 0.6572 to 13.2631 & 0.1578 \\
\hline \multicolumn{4}{|l|}{ RFS } \\
\hline MUC5B (positive vs negative) & 0.2913 & 0.1233 to 0.6886 & 0.005 \\
\hline Stage I vs stage II/III & 0.5937 & 0.2735 to 1.2888 & 0.1874 \\
\hline Lymphatic invasion (positive vs negative) & 3.7624 & 1.5294 to 9.2556 & 0.0039 \\
\hline
\end{tabular}


A

EGFR mutant type NSCLC

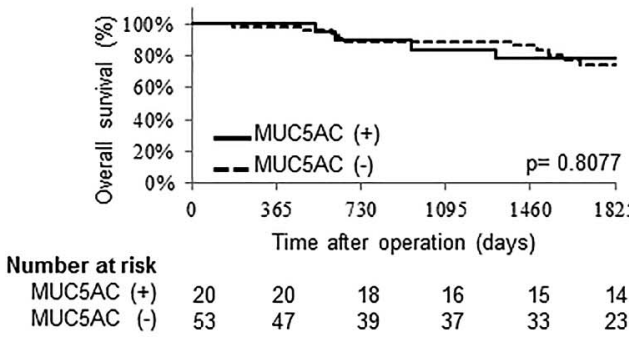

B

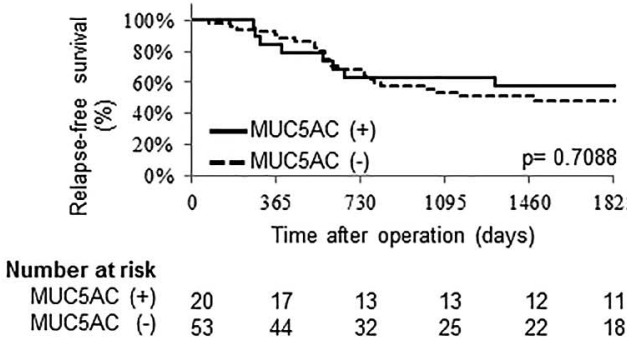

C

EGFR wild type NSCLC

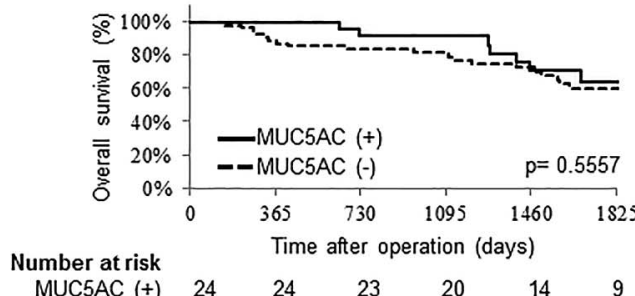

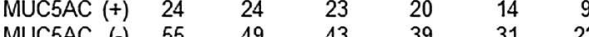

$\mathrm{D}$

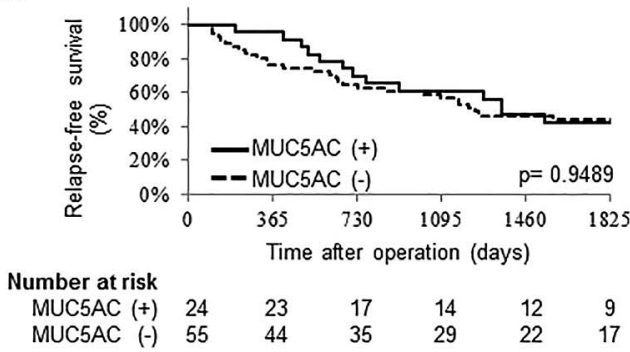

Figure 3 Survival curves for patients based on the expression of MUC5AC in epidermal growth factor receptor (EGFR) mutant or wild type non-small cell lung cancer (NSCLC). Overall and relapse-free survivals (OS and RFS) for patients with NSCLC carrying EGFR mutations or EGFR wild type. OS (A) RFS (B) in the patients with EGFR-mutant type NSCLC and OS (C) and RFS (D) in the patients with EGFR wild-type NSCLC.

clearance and innate immunity against bacterial infection. ${ }^{28}$ The potential functions of MUC5B in lung cancer, including EGFR mutant lung cancer, are not known. The present study suggests that MUC5B or processes regulating $M U C 5 B$ may influence the growth and metastasis of EGFR mutant NSCLC. MUC5B may serve as a surrogate biomarker influenced by a pathway involved in metastasis and recurrence associated with EGFR mutant NSCLC.

In conclusion, our data revealed the clinicopathological significance of MUC5B as a favourable prognostic factor in resected EGFR mutant NSCLC. Further studies are necessary to elucidate the gene regulatory mechanism and the function of MUC5B in EGFR mutant NSCLC.

Acknowledgements The authors would like to thank the patients, their families, all of the investigators who participated in the study, the central laboratories that carried out the EGFR mutation testing and Dr Mary Durbin for discussions.

Contributors KW, TT, JAW, YM and TN participated in conception and design. $\mathrm{KW}, \mathrm{TT}, \mathrm{KT}$, KTa, NY, KM, TM, AN, JAW and YM were involved in provision of study material, patients and data acquisition. KW, TT, KTo, KM, JAW, YM and TN were involved in data analysis and interpretation. KW, TT, JAW, YM and TN were responsible for drafting manuscript and intellectual content.

Funding This work was supported by the Ministry of Education, Science, and Culture of Japan, National Institute of Health, American Lung Association, the University of Cincinnati Postdoctoral Fellow Research Program and Cincinnati Children's Hospital Medical Center

Competing interests None declared.

Patient consent Obtained.

Ethics approval Ethics Committee from every participant hospital.

Provenance and peer review Not commissioned; externally peer reviewed.
Data sharing statement No additional data available.

Open Access This is an Open Access article distributed in accordance with the Creative Commons Attribution Non Commercial (CC BY-NC 4.0) license, which permits others to distribute, remix, adapt, build upon this work noncommercially, and license their derivative works on different terms, provided the original work is properly cited and the use is non-commercial. See: http:// creativecommons.org/licenses/by-nc/4.0/

\section{REFERENCES}

1. Siegel R, Naishadham D, Jemal A. Cancer statistics for hispanics/ latinos, 2012. CA Cancer J Clin 2012;62:283-98.

2. Lynch T, Bell D, Sordella R, et al. Activating mutations in the epidermal growth factor receptor underlying responsiveness of non-small-cell lung cancer to gefitinib. $N$ Engl $J$ Med 2004;350:2129-39.

3. Paez JG, Jänne PA, Lee JC, et al. EGFR mutations in lung cancer: correlation with clinical response to gefitinib therapy. Science 2004;304:1497-500.

4. Camidge DR, Pao W, Sequist LV. Acquired resistance to TKIs in solid tumours: learning from lung cancer. Nat Rev Clin Oncol 2014;11:473-81.

5. Shames DS, Wistuba II. The evolving genomic classification of lung cancer. J Pathol 2014;232:121-33.

6. Maeda Y, Tsuchiya T, Hao H, et al. KrasG12D and Nkx2-1 haploinsufficiency induce mucinous adenocarcinoma of the lung. J Clin Invest 2012;122:4388-400.

7. Travis WD, Brambilla E, Noguchi M, et al. International Association for the Study of Lung Cancer/American Thoracic Society/European Respiratory Society: international multidisciplinary classification of lung adenocarcinoma: executive summary. Proc Am Thorac Soc 2011;8:381-5

8. Wolff AC, Hammond MEH, Hicks DG, et al. Recommendations for human epidermal growth factor receptor 2 testing in breast cancer: American Society of Clinical Oncology/College of American Pathologists clinical practice guideline update. J Clin Oncol 2013;31:3997-4013.

9. Yu CJ, Yang PC, Shun CT, et al. Overexpression of MUC5 genes is associated with early post-operative metastasis in non-small-cell lung cancer. Int $J$ Cancer 1996;69:457-65.

10. Pinto-de-Sousa J, Reis CA, David L, et al. MUC5B expression in gastric carcinoma: relationship with clinico-pathological parameters 
and with expression of mucins MUC1, MUC2, MUC5AC and MUC6. Virchows Arch 2004;444:224-30.

11. Varangot $M$, Barrios $E$, Sóñora $C$, et al. Clinical evaluation of a panel of mRNA markers in the detection of disseminated tumor cells in patients with operable breast cancer. Oncol reports 2005;14:537-45.

12. Partheen $\mathrm{K}$, Levan $\mathrm{K}$, Osterberg $\mathrm{L}$, et al. Expression analysis of stage III serous ovarian adenocarcinoma distinguishes a sub-group of survivors. Eur J Cancer 2006;42:2846-54.

13. Valque H, Gouyer V, Gottrand F, et al. MUC5B leads to aggressive behavior of breast cancer MCF7 cells. PLoS ONE 2012;7:e46699.

14. Nagashio R, Ueda J, Ryuge S, et al. Diagnostic and prognostic significances of MUC5B and TTF-1 expressions in resected non-small cell lung cancer. Sci Rep 2015;5:8649.

15. Mizuno H, Kitada K, Nakai K, et al. PrognoScan: a new database for meta-analysis of the prognostic value of genes. BMC Med Genomics 2009;2:18

16. Shedden K, Taylor JMG, Enkemann SA, et al. Director's Challenge Consortium for the Molecular Classification of Lung Adenocarcinoma. Gene expression-based survival prediction in lung adenocarcinoma: a multi-site, blinded validation study. Nat Med 2008;14:822-7.

17. Okayama $\mathrm{H}$, Kohno $\mathrm{T}$, Ishii $\mathrm{Y}$, et al. Identification of genes upregulated in ALK-positive and EGFR/KRAS/ALK-negative lung adenocarcinomas. Cancer Res 2012;72:100-11.

18. Bild AH, Yao G, Chang JT, et al. Oncogenic pathway signatures in human cancers as a guide to targeted therapies. Nature 2006:439:353-7.

19. Zhu CQ, Ding K, Strumpf D, et al. Prognostic and predictive gene signature for adjuvant chemotherapy in resected non-small-cell lung cancer. J Clin Oncol 2010;28:4417-24.
20. Lee ES, Son DS, Kim SH, et al. Prediction of recurrence-free survival in postoperative non-small cell lung cancer patients by using an integrated model of clinical information and gene expression. Clin Cancer Res 2008:14:7397-404.

21. Raponi M, Zhang $\mathrm{Y}, \mathrm{Yu} \mathrm{J}$, et al. Gene expression signatures for predicting prognosis of squamous cell and adenocarcinomas of the lung. Cancer Res 2006;66:7466-72.

22. Pawitan Y, Bjöhle J, Amler L, et al. Gene expression profiling spares early breast cancer patients from adjuvant therapy: derived and validated in two population-based cohorts. Breast Cancer Res 2005; 7:R953-64.

23. Miller LD, Smeds J, George J, et al. An expression signature for p53 status in human breast cancer predicts mutation status, transcriptional effects, and patient survival. Proc Natl Acad Sci USA 2005;102:13550-5.

24. Chanrion $\mathrm{M}$, Negre $\mathrm{V}$, Fontaine $\mathrm{H}$, et al. A gene expression signature that can predict the recurrence of tamoxifen-treated primary breast cancer. Clin Cancer Res 2008;14:1744-52.

25. Evans C, Kim K, Tuvim M, et al. Mucus hypersecretion in asthma: causes and effects. Curr Opin Pulm Med 2009;15:4-11.

26. Plantier L, Crestani B, Wert SE, et al. Ectopic respiratory epithelial cell differentiation in bronchiolised distal airspaces in idiopathic pulmonary fibrosis. Thorax 2011;66:651-7.

27. Seibold M, Wise A, Speer M, et al. A common MUC5B promoter polymorphism and pulmonary fibrosis. N Engl J Med 2011;364:1503-12.

28. Roy MG, Livraghi-Butrico A, Fletcher AA, et al. Muc5b is required for airway defence. Nature 2014;505:412-16. 